\title{
Atitudes Sociais de Agentes Educacionais em Relaçáo à Inclusão e à FormaÇấo em ANálise do Comportamento Aplicada ${ }^{1}$ \\ SOCIAL ATTITUDES OF EDUCATIONAL A GENTS TOWARDS INCLUSION AND TRAINING IN APPLIED BEHAVIOR ANALYSIS
}

\author{
Priscila BENITEZ ${ }^{2}$ \\ Vanessa Cristina PAULINO ${ }^{3}$ \\ Ailton Paulo OLIVEIRA JR. ${ }^{4}$ \\ Camila DOMENICONI ${ }^{5}$ \\ Sadao OMOTE ${ }^{6}$
}

\begin{abstract}
RESUMO: As atitudes sociais dos agentes educacionais podem influenciar o desenvolvimento de práticas inclusivas no contexto escolar. Considerando os principais desafios da inclusão escolar de estudantes com Transtorno do Espectro Autista (TEA) na rede regular de ensino, esta pesquisa teve como objetivo avaliar atitudes sociais de agentes educacionais formais e informais em relação à inclusão antes e após um programa de formação em Educação Especial e Inclusiva fundamentado na Análise do Comportamento Aplicada. Participaram 52 agentes educacionais. O programa foi composto por encontros de discussóes teóricas, atividades práticas e leitura dirigida sobre Educação Especial e Inclusiva e sobre estratégias analítico-comportamentais para intervenção. As atitudes sociais em relação à inclusão foram mensuradas por meio da Escala Likert de Atitudes Sociais em relação à inclusão antes e após a formação. O teste de Wilcoxon apontou diferença estatisticamente significante entre os escores do pré-teste e pós-teste ( $\mathrm{p}=0,003)$. Foram discutidas as implicações do programa formativo proposto sobre as possibilidades de desenvolvimento de um ambiente escolar inclusivo, uma vez que essa capacitação resultou em atitudes sociais mais favoráveis dos cursistas em relação à inclusão.
\end{abstract}

PALAVRAS-CHAVE: Análise do Comportamento Aplicada. Atitudes sociais. Inclusão. Agentes educacionais. Transtorno do Espectro Autista.

ABSTRACT: The social attitudes of educational agents can influence the development of inclusive practices in the school context. Considering the main challenges of school inclusion of students with Autism Spectrum Disorder (ASD) in the regular school system, this research aimed to evaluate the social attitudes of formal and informal educational agents concerning inclusion, before and after a program of training in Special and Inclusive Education, based on the Applied Behavior Analysis. Fifty-two educational

\footnotetext{
${ }^{1}$ https://doi.org/10.1590/1980-54702021v27e0125

${ }^{2}$ Doutora em Psicologia pela Universidade Federal de São Carlos (UFSCar). Professora Adjunta no Centro de Matemática, Computação e Cogniçáo da Universidade Federal do ABC. Pesquisadora no Instituto Nacional de Ciência e Tecnologia sobre Comportamento, Cognição e Ensino (INCT-ECCE) (Deisy G. de Souza, presidente) financiado pelo Conselho Nacional de Desenvolvimento Científico e Tecnológico (CNPq) (Processo \#573972/2008-7) e Fundação de Amparo à Pesquisa do Estado de São Paulo (FAPESP) (2008/57705-8). Santo André/São Paulo/Brasil. E-mail: priscila.benitez@ufabc.edu.br. ORCID: http://orcid. org/0000-0003-3501-7606

${ }^{3}$ Doutora em Educação Especial pela UFSCar. Pedagoga com Habilitação em Deficiência Visual. Técnica em Assuntos Educacionais do Curso de Licenciatura em Educação Especial da UFSCar. São Carlos/São Paulo/Brasil. E-mail: vanessakju@gmail.com. ORCID: https://orcid.org/0000-0003-0063-0355

${ }^{4}$ Doutor em Educação pela Universidade de São Paulo (USP). Professor Associado na Universidade Federal do ABC (UFABC). Pesquisador no Instituto Nacional de Ciência e Tecnologia sobre Comportamento, Cognição e Ensino (INCT-ECCE), financiado pelo CNPq (\#573972/2008-7) e FAPESP (2008/57705-8). Santo André/São Paulo/Brasil. E-mail: ailton.junior@ufabc.edu.br. ORCID: http://orcid.org/0000-0002-2721-7192

${ }^{5}$ Doutora em Educação Especial pela UFSCar. Professora Associada do Departamento de Psicologia e do Programa de Pós-Graduação em Psicologia (DeptoPsi/PPGPsi), UFSCar, Instituto Nacional de Ciência e Tecnologia sobre Comportamento, Cognição e Ensino (INCT-ECCE), financiado pelo CNPq (\#573972/2008-7) e FAPESP (2008/57705-8). São Carlos/São Paulo/Brasil. E-mail: domeniconicamila@gmail.com. ORCID: http://orcid.org/0000-0003-0486-3543

${ }^{6}$ Professor Titular do Departamento de Educação Especial da Faculdade de Filosofia e Ciências, Universidade Estadual Paulista (UNESP). Professor Orientador do Programa de Pós-Graduação em Educação, UNESP, Marília. Pesquisador 1-B do CNPq. Líder do grupo de pesquisa Diferença, Desvio e Estigma. Marília/São Paulo/Brasil. E-mail: somote@uol.com.br. ORCID: https://orcid. org/0000-0003-2455-4529
} 
agents participated. The program was composed of meetings for theoretical discussions, practical activities, and guided reading on Special and Inclusive Education and analytical-behavioral strategies for intervention. Social attitudes toward inclusion were measured through the Likert Scale of Social Attitudes toward Inclusion before and after the training. Wilcoxon's test revealed a statistically significant difference between the pre-test scores and post-test scores $(p=0.003)$. The implications of the proposed training program on the possibilities for the development of an inclusive school environment were discussed, since this training resulted in more favorable social attitudes of the educators toward inclusion.

KEYWORDS: Applied Behavior Analysis; Social attitudes; Inclusion; Educational agents; Autism Spectrum Disorder.

\section{INTRODUÇÁo}

A Agenda Mundial estabelecida pelos países integrantes da Organização das Naçóes Unidas (ONU, 2015) instituiu 17 Objetivos de Desenvolvimento Sustentável para o Milênio, visando à transformação mundial em busca de uma sociedade mais justa e igualitária. Dentre eles, o quarto objetivo trata especificamente de "assegurar a Educação Inclusiva, equitativa, de qualidade e promover oportunidades de aprendizagem ao longo da vida para todos" (ONU, 2015). Mediante tal perspectiva, entende-se que a educação é um direito fundamental e indispensável para a promoção do desenvolvimento sustentável.

O direito à educação envolve o trabalho com os diferentes grupos sociais, com destaque ao público-alvo da Educação Especial, compreendendo pessoas com deficiência, transtornos globais do desenvolvimento ${ }^{7}$ e altas habilidades/superdotação, conforme delineado na Política Nacional de Educação Especial na Perspectiva da Educação Inclusiva - PNEEPEI (2008). Tal trabalho implica não apenas o acesso a oportunidades educacionais, como também a permanência e o aproveitamento pleno dessas oportunidades. Essa perspectiva inclusiva está presente em diferentes países e foi engendrada após a Declaraçăo de Educação para Todos (Organizaçâo das Naçôes Unidas para a Educação, a Ciência e a Cultura [UNESCO], 1990) e principalmente pela Declaração de Salamanca (UNESCO, 1994). A partir dessa perspectiva, foi possível modificar o modelo da deficiência centrado na pessoa para o modelo social da deficiência, com ênfase em seu meio, de modo a garantir que o ambiente seja inclusivo para todas as pessoas, fomentando o enfoque das abordagens sociais no estudo da deficiência (Omote, 2018).

Garantir o direito educacional do público-alvo da Educação Especial nas escolas regulares brasileiras ainda é um desafio a ser superado, especialmente em relaçáo a estudantes com Transtorno do Espectro Autista (TEA), conforme apontam os professores entrevistados por Rodrigues et al. (2012). Além disso, o estudo de Schmidt et al. (2016) evidencia que o TEA é uma condição pouco conhecida pelos professores, que indicam a falta de formação para criar e prover condiçôes adequadas de ensino e de aprendizagem destinadas a esse público.

Uma variável crítica recorrentemente identificada na literatura sobre formação de professores refere-se aos componentes curriculares obrigatórios nos cursos de formação inicial de professores relacionados ao ensino e à aprendizagem com práticas inclusivas voltadas ao ensino de qualidade para todos os estudantes da mesma sala de aula, independentemente de sua condição (França \& Munford, 2012; Monico et al., 2018; Pletsch, 2009). Além disso, a

\footnotetext{
${ }^{7}$ Dentre os Transtornos Globais do Desenvolvimento, conforme previsto nos documentos político-normativos educacionais brasileiros, encontra-se o Transtorno do Espectro Autista, público-alvo deste estudo.
} 
formação inicial de professores nas diversas áreas mostra a carência de conteúdos pedagógicos capazes de auxiliá-los na elaboração de estratégias pedagógicas inclusivas, de modo a garantir a aprendizagem dos estudantes público-alvo da Educação Especial (França \& Munford, 2012).

Apesar das iniciativas de estudos brasileiros voltados à formação de professores a partir do planejamento de práticas inclusivas (Benitez \& Domeniconi, 2015, Calheiros \& Mendes, 2016; Vilaronga \& Mendes, 2017), existe urgência em garantir "formação continuada aos professores que seja centrada na identificação dos sinais de alerta do autismo e difusão de práticas de intervenção, uma vez que a educação infantil se constitui em cenário natural para este fim" (Schmidt, 2017, p. 228). A formação continuada dos professores visando ao ensino e à aprendizagem de estudantes com TEA tem sido considerada uma estratégia relevante (Schmidt et al., 2016).

O TEA tem como características definidoras o comprometimento qualitativo nas interações sociais e na comunicação, além de interesses e atividades restritos e repetitivos. Essas características são identificadas a partir de critérios clínicos estabelecidos pelos manuais oficiais (Associação Americana de Psiquiatria [APA], 2013). O desenvolvimento idiossincrático desencadeado pelo TEA provoca alteraçóes específicas na sequência e na qualidade do desenvolvimento, o que dificulta o estabelecimento de intervenções educacionais eficazes. Devido ao excesso comportamental ou à ausência de repertório, somado à ausência ou ao déficit na linguagem e nas habilidades sociais, a aprendizagem dos estudantes com TEA é motivo de muitas discussóes, sobretudo nos espaços de sala de aula comum (Rodrigues et al., 2012, Schmidt, 2017).

O TEA pode acometer diferentes áreas do desenvolvimento, razão pela qual os estudantes podem necessitar de trabalhos que incrementem as diferentes habilidades, como a linguagem (receptiva e expressiva), o desenvolvimento cognitivo (com destaque para habilidades acadêmicas), as habilidades sociais, o desenvolvimento motor e a autonomia (Higbee, 2012). A intervenção eficaz para estudantes com TEA envolve, portanto, uma programação detalhada de atividades que integram o desenvolvimento (Carvalho et al., 2013). Isso requer o trabalho conjunto de diferentes profissionais (das áreas da saúde e da educação), o que pode favorecer a abrangência de conhecimento nesse âmbito de investigação (Velloso et al., 2011), além de atender às normativas oficiais, no que concerne ao trabalho multiprofissional com o estudante com TEA, conforme a Lei no 12.764 , de 27 de dezembro de 2012.

Nesse contexto, a literatura científica tem mostrado empiricamente a eficácia de procedimentos de ensino para crianças com TEA, especialmente quando envolvem intervenção precoce e intensiva (Gomes et al., 2017), fundamentada na Análise do Comportamento Aplicada (ABA). Para que a eficácia possa ser replicada nas intervençóes, devem ser contemplados certos princípios, tais como: avaliar o repertório comportamental com o uso de instrumentos sistematizados; identificar o comportamento-alvo a ser ensinado, de acordo com os dados da avaliação; identificar o repertório de habilidades básicas; elaborar um currículo amplo, envolvendo diferentes habilidades; garantir carga horária para promover uma intervenção intensiva (com frequência de aplicação das sessóes, em torno de 25 horas semanais); sistematizar a intervenção, com ênfase na generalização e em objetivos individualizados de aprendizagem; iniciar a intervenção o mais precoce possível (Cooper et al., 2007; Maurice et al., 1996); e criar condiçóes para a participação dos pais ao longo da intervenção. 
São apontados como comportamentos que podem ser avaliados e ensinados: imitar, fazer e manter contato e rastreamento visual, iniciar e finalizar uma atividade, seguir instrução e outros (Gomes \& Silveira, 2016; Higbee, 2012; Maurice et al., 1996). De maneira geral, o acesso à ABA, como ciência, no Brasil, está restrito às famílias providas de recursos privados, uma vez que os analistas do comportamento (profissionais que aplicam a intervenção comportamental, como psicólogo, fonoaudiólogo, pedagogo, terapeuta ocupacional, educador especial etc.) não são encontrados nas redes públicas de educação e de saúde com a frequência e a carga horária necessárias para atender à demanda.

Estratégias para tornar o uso dessas técnicas acessível a diferentes públicos podem ser viáveis a partir de programas de formação que garantam o envolvimento de diferentes agentes educacionais. Tal prática pode propiciar reflexóes sobre o uso de estratégias analítico-comportamentais para o ensino e a aprendizagem de comportamentos específicos (como sociais e pedagógicos) de estudantes com TEA. A relação entre o agente educacional e o estudante com TEA precisa estar orientada por atitudes sociais favoráveis ao processo inclusivo desse público-alvo.

Os comportamentos sociais dos atores envolvidos no processo inclusivo, em consonância com as atitudes sociais favoráveis à inclusão, são componentes fundamentais na Educação Inclusiva, uma vez que a barreira atitudinal acaba por contaminar as medidas adotadas justamente para acolher o estudante com TEA. Como consequência, as experiências educacionais podem resultar em insucessos, que não devem ser creditados à suposta dificuldade do próprio aluno. Uma forma de estudar os comportamentos sociais pode ser por meio das atitudes sociais, pois elas subjazem tais comportamentos (Omote, 2013, 2016, 2018).

As atitudes sociais dos educadores em relação à inclusão são variadas, o que resulta em condiçóes mais ou menos favoráveis à inclusão. Naturalmente, os estudantes com TEA apresentam ampla variação nas suas dificuldades e particularidades. Por isso, no processo inclusivo, compete aos educadores encontrar um procedimento adequado para cada aluno especial. $\mathrm{Na}$ construção desse processo inclusivo, muitos empecilhos interpóem-se, alguns facilmente identificáveis e outros mais encobertos e não tão fáceis de distinguir.

Uma dessas grandes barreiras é a atitudinal, que pode orientar açóes de modo dissimulado. $\mathrm{O}$ estudo das atitudes sociais em relação à inclusão revela ampla possibilidade de modificação de tais atitudes, a partir de intervenções programadas com esse fim e com uso de instrumentos confiáveis que permitam mensurar os resultados (Omote, 2018).

Torres e Mendes (2019) desenvolveram e implementaram um programa de formação inicial de professores para Educação Especial, via Moodle, o qual versa sobre História, Políticas e Práticas Pedagógicas na Educação Inclusiva. As mensurações antes e após o curso não identificaram mudanças nas atitudes sociais dos cursistas. $\mathrm{O}$ conteúdo desenvolvido nesse curso pode não ter convencido os professores participantes sobre a exequibilidade de um projeto de Educação Inclusiva.

Ao considerar o formato dos cursos e os dados envolvendo a alteração ou não de atitudes sociais documentados na literatura anterior, como em Torres e Mendes (2019) - cujo curso de formação não produziu mudança nas atitudes sociais dos participantes -, e os cursos propostos por Shade e Stewart (2001), Lenka e Parua (2012), Vieira (2014) e Menino-Mencia 
(2020), que evidenciaram a ocorrência de mudança nas atitudes sociais dos participantes -possivelmente pela presença de atividades práticas tratando da inclusão, além de assuntos teóricos -, a hipótese deste estudo foi de que um curso que criasse condições para a formação de professores no uso da ciência ABA poderia sugerir-lhes caminhos para o enfrentamento de dificuldades que podem surgir na educação escolar de estudantes com TEA em classes de ensino comum.

Nessa perspectiva, o objetivo da pesquisa foi verificar a possibilidade de modificação de atitudes sociais de agentes educacionais formais e informais em relação à inclusão por meio da capacitação deles em ABA para planejar e intervir, visando à consecução de objetivos comportamentais específicos com estudantes com TEA.

A originalidade do estudo envolveu a proposta de um curso com o objetivo de formar os educadores para o uso da ABA, sem nenhuma atividade com vistas à modificação de atitudes sociais. Apesar disso, ocorreram mudanças significativas, possivelmente pelo fato de os cursistas terem percebido a possibilidade de intervenção junto a estudantes com TEA. Além da importância de introduzir atividades práticas, baseadas na $\mathrm{ABA}$, que permitam aos professores visualizar a possibilidade de intervenção efetiva para promover a inclusão, o estudo trata das atitudes sociais dos educadores em relação à inclusão, as quais são variáveis pessoais importantes na construção da Educação Inclusiva.

\section{Método}

Este trabalho foi aprovado pelo Comitê de Ética da Universidade Federal do ABC. Os participantes assinaram o Termo de Consentimento Livre e Esclarecido (TCLE) para participação na pesquisa. Dito isso, nesta seção, delineiam-se as características da amostra de participantes, os materiais utilizados para coleta de dados, a programação do curso e o procedimento de coleta e análise de dados.

\subsection{Participantes}

A amostra foi constituída de 52 participantes com diferentes ocupaçóes que estavam frequentando um curso de extensão oferecido por uma Universidade pública em conjunto à Secretaria Municipal de Educação de uma cidade do interior do Estado de São Paulo. O curso era destinado a professores de Atendimento Educacional Especializado (AEE) e a professores itinerantes, cuja função é assessorar os docentes em classes com algum estudante público-alvo da Educação Especial matriculado. Foram também convidados a participar do curso os pais que faziam parte de um grupo de pesquisa sobre Educação Especial e Inclusiva, estudantes universitários e interessados da comunidade em geral. Houve manifestação de grande número de interessados, com mais de 500 inscritos. Como o espaço no qual o curso seria oferecido acomodava um número menor de pessoas, 160 vagas foram preenchidas de acordo com a ordem de inscrição. Dos 160 inscritos, 151 concluíram o curso e 52 concordaram em participar da pesquisa.

Cinquenta e um participantes eram do sexo feminino e um do sexo masculino. A idade cronológica variou de 25 a 62 anos, com a média de 41,43 anos e o desvio padrão de 
10,12 anos. Dentre os participantes, 25 tinham Pós-Graduação (lato sensu e/ou stricto sensu), 25 tinham curso superior completo e dois cursavam um bacharelado interdisciplinar. Quanto à profissão, a amostra foi constituída de 15 professoras assessoras de Educação Inclusiva, 10 professoras, seis professoras de Educação Infantil, quatro professoras de Educação Especial (que optaram por não especificar suas respectivas atuaçóes, podendo atuar de modo itinerante nas escolas, no coensino ou como assessoras das professoras da sala comum), quatro professoras de AEE, duas assistentes pedagógicas, duas coordenadoras pedagógicas, dois psicólogos, duas mães de filho com TEA, dois estudantes de Graduação, uma professora de ensino profissionalizante, uma psicopedagoga e uma pedagoga.

\subsection{Materiais}

Para a mensuração das atitudes sociais, foi utilizada a Escala Likert de Atitudes Sociais em relação à Inclusão (ELASI), formas A e B (equivalentes). Cada item da escala se constitui de um enunciado acompanhado de cinco alternativas, que expressam diferentes graus de concordância ou discordância com relação ao seu conteúdo: concordo inteiramente, concordo mais ou menos, nem concordo nem discordo, discordo mais ou menos e discordo inteiramente. Metade dos itens é positiva e a outra metade negativa, sendo o item positivo quando a concordância com o conteúdo do enunciado expressa atitudes sociais favoráveis à inclusão e vice-versa (Omote, 2005). Além disso, uma ficha de identificação dos participantes foi utilizada para o levantamento de algumas variáveis sociodemográficas para verificar possível relação entre elas e as atitudes sociais relacionadas à inclusão, bem como a provável correspondência com as mudanças atitudinais ocorridas.

\subsection{Programa de formaçáo}

A programação do curso de capacitação foi desenvolvida por meio de aulas presenciais e atividades realizadas em domicílio. As atividades domiciliares compreendiam leituras por meio de roteiro de estudo e realização de trabalho prático. As aulas presenciais foram ministradas na Universidade, e todo o material das atividades domiciliares foi enviado por e-mail. O Quadro 1 descreve a estrutura básica estabelecida no programa formativo, dividida em duas partes: a primeira mais teórica acerca do panorama geral da Educação Especial e Inclusiva, e a outra mais específica sobre as estratégias em ABA para o trabalho com o estudante com TEA.

\section{Quadro 1}

Estrutura geral das atividades programáticas da capacitaçâo

\begin{tabular}{|l|l|}
\hline \multicolumn{1}{|c|}{ Aula/Entrega } & \multicolumn{1}{c|}{ Conteúdo } \\
\hline Aula presencial 1 & $\begin{array}{l}\text { Aplicação da ELASI. } \\
\text { Apresentaçáo do cronograma. Educação Especial e Inclusiva: discussão preliminar acerca dos } \\
\text { seus conceitos. Contexto histórico e político da Educação Especial na perspectiva da Educação } \\
\text { Inclusiva. }\end{array}$ \\
\hline $\begin{array}{l}\text { Entrega do roteiro de } \\
\text { estudos 1 e Prática 1 }\end{array}$ & $\begin{array}{l}\text { Roteiro de estudos 1: Mendes (2006) e Omote (1999). } \\
\text { Prática 1: Análise do momento histórico de uma escola. }\end{array}$ \\
\hline
\end{tabular}




\begin{tabular}{|c|c|}
\hline Aula presencial 2 & $\begin{array}{l}\text { Resolução do roteiro de estudos } 1 \text {. Diretrizes políticas atuais da Educação Especial na perspectiva } \\
\text { da Educaçáo Inclusiva no Brasil. Definição do público-alvo da Educaçâo Especial com enfoque } \\
\text { no Transtorno do Espectro Autista (TEA). Desafios da Educaçáo Inclusiva no Brasil: profissio- } \\
\text { nais, serviços e currículo. }\end{array}$ \\
\hline $\begin{array}{l}\text { Entrega do roteiro de } \\
\text { estudos } 2 \text { e Prática } 2\end{array}$ & $\begin{array}{l}\text { Roteiro de estudos 2: Benitez et al. (2017). } \\
\text { Prática 2: Caracterização do estudante-alvo e das estratégias inclusivas. }\end{array}$ \\
\hline Aula presencial 3 & $\begin{array}{l}\text { Resoluçáo do roteiro de estudos 2. Conceitos básicos de aprendizagem em Análise do Comporta- } \\
\text { mento. Procedimentos de ensino na perspectiva da Análise do Comportamento. }\end{array}$ \\
\hline $\begin{array}{l}\text { Entrega do roteiro de } \\
\text { estudos } 3 \text { e Prática } 3\end{array}$ & $\begin{array}{l}\text { Roteiro de estudos 3: Domeniconi et al. (2012). } \\
\text { Prática 3: Planejamento do ensino: escolha das consequências, organizaçáo do atendimento, } \\
\text { definiçáo do procedimento (ensino incidental, tentativa discreta). }\end{array}$ \\
\hline Aula presencial 4 & $\begin{array}{l}\text { Resolução do roteiro de estudos } 3 \text {. O primeiro encontro com o estudante com TEA: avaliação } \\
\text { comportamental. }\end{array}$ \\
\hline $\begin{array}{l}\text { Entrega do roteiro de } \\
\text { estudos } 4 \text { e Prática } 4\end{array}$ & $\begin{array}{l}\text { Roteiro de estudos 4: Williams e Aiello (2001). } \\
\text { Prática 4: Aplicação de uma avaliação e definiçấo do comportamento-alvo para o ensino. }\end{array}$ \\
\hline Aula presencial 5 & $\begin{array}{l}\text { Resolução do roteiro de estudos } 4 \text {. Transformando os resultados da avaliação comportamental em } \\
\text { programas de ensino: elaboraçáo do currículo individualizado. Serviço interdisciplinar em ABA } \\
\text { para estudantes com TEA: organização e caracterizaçâo. }\end{array}$ \\
\hline $\begin{array}{l}\text { Entrega do roteiro de } \\
\text { estudos } 5 \text { e Prática } 5\end{array}$ & $\begin{array}{l}\text { Roteiro de estudos 5: Domeniconi et al. (2012) e Almeida-Verdu et al. (2012). } \\
\text { Prática 5: Organizaçấo do estudo de caso/currículo. }\end{array}$ \\
\hline Aula presencial 6 & $\begin{array}{l}\text { Aplicação da ELASI. Resolução do roteiro de estudos 5. Seminário: Apresentação dos currículos } \\
\text { individualizados elaborados pelos cursistas. }\end{array}$ \\
\hline
\end{tabular}

O programa de formação foi composto pela carga horária total de 60 horas distribuídas em seis aulas presenciais, no total de 18 horas, 20 horas para atividades práticas (distribuídas em 15 horas para execuçáo e cinco horas para produção de relatório previsto para cada atividade prática), 12 horas para leitura dos textos científicos e dez horas para realização dos roteiros de estudos. As estratégias pedagógicas utilizadas durante os encontros presenciais envolveram discussão e debate em grupo, aulas expositivas dialogadas, estudo e discussão dos textos científicos, produção de síntese e seminário.

\subsection{Procedimento de COleta E ANÁlise de dados}

Antes do início das atividades da capacitação e imediatamente após a conclusão delas, foi aplicada a ELASI para aferir se a realização das atividades e a participação nas aulas presenciais contribuíram para a modificação das atitudes sociais em relação ao processo de inclusão escolar. No pré-teste, foi aplicada a forma $A$; no pós-teste, a forma $B^{8}$.

Para a análise de dados, preliminarmente foram calculados os escores individuais de atitudes sociais em relação à inclusão. As diferentes análises foram feitas com base nesses escores. Inicialmente, foram comparados os escores do pré-teste e os do pós-teste de todos os participantes da pesquisa. Na sequência, foram feitas análises em função de três variáveis pessoais e de duas variáveis relativas à participação no curso. As variáveis pessoais consideradas foram: a atuação ou não na Educação Especial, a idade cronológica e o nível de escolaridade. As

\footnotetext{
${ }^{8}$ Embora as duas formas tenham sido construídas para serem equivalentes, não há garantia de que essa equivalência se mantenha constante em qualquer amostra. Teria sido mais adequada a utilização das formas A e B nas duas avaliaçóes, distribuídas de tal maneira que os participantes respondessem a uma forma no pré-teste e à outra no pós-teste.
} 
variáveis relativas à participação no curso foram a quantidade de trabalhos entregues e o tempo de participação no curso. É fundamental ressaltar que a escolha das três variáveis pessoais foi feita com base em pesquisas que evidenciaram a relação entre essas variáveis e as atitudes sociais relacionadas à inclusão. A escolha das duas variáveis relativas à participação no curso foi justificada como parte integrante do objetivo da pesquisa.

\section{Resultados}

Inicialmente, foram calculados os escores individuais de atitudes sociais em relação à inclusão de todos os participantes no pré-teste e no pós-teste. A síntese desses dados é apresentada na Tabela 1, por meio da variação representada pelo menor escore (Min) e maior escore (Max), medida de tendência central representada pela mediana (Md) e dispersão representada pelo quartil 1 (Q1) e pelo quartil 3 (Q3).

\section{Tabela 1}

Escores de atitudes sociais em relação à inclusão no pré-teste e no pós-teste

\begin{tabular}{c|c|c|c}
\hline Avaliaçáo & $\begin{array}{c}\text { Variaçáo } \\
\text { (Min-Max })\end{array}$ & $\begin{array}{c}\text { Mediana } \\
(\mathbf{M d})\end{array}$ & $\begin{array}{c}\text { Dispersão } \\
\text { (Q1-Q3) }\end{array}$ \\
\hline Pré-teste & $37-150$ & 141 & $135,25-143,5$ \\
\hline Pós-teste & $123-150$ & 143,5 & $145-147$ \\
\hline
\end{tabular}

Legenda: Min = menor escore; Max = maior escore; Md = mediana; Q1 = primeiro quartil; Q3 = terceiro quartil.

Os dados da Tabela 1 sugerem que, do pré-teste para o pós-teste, os escores tendem a ser deslocados para cima, indicando atitudes sociais mais favoráveis. Comparando os escores do pré-teste com os do pós-teste, por meio da prova de Wilcoxon, verificou-se haver diferença estatisticamente significante $(\mathrm{p}=0,003)$ entre os dois momentos de avaliação das atitudes sociais em relação à inclusão. Evidencia-se que o curso de capacitação oferecido teve efeito significante sobre as atitudes sociais dos participantes, tornando-as mais favoráveis à inclusão.

Como o grupo de participantes era bastante heterogêneo em suas características, procedeu-se a uma análise detalhada para identificar possíveis variáveis mais estreitamente associadas às atitudes sociais em relação à inclusão. Nessa análise, os participantes foram distribuídos em dois subgrupos para cada uma das cinco variáveis consideradas.

Os escores obtidos por esses subgrupos no pré-teste foram comparados por meio da prova de Mann-Whitney para cada variável. O resultado dessa análise pode ser visto na Tabela 2. Somente em relação à variável "Escolaridade", foi observada diferença estatisticamente significante entre os subgrupos no pré-teste $(\mathrm{p}=0,043)$. Os participantes com formação em nível de Pós-Graduação apresentavam, antes do curso, atitudes sociais em relação à inclusão significantemente diferentes de seus pares com formação apenas em nível de Graduação. Além disso, as atitudes sociais não se diferenciam significantemente entre os subgrupos das demais variáveis. 


\section{Tabela 2}

Comparação dos escores do pré-teste dos subgrupos para cada variável

\begin{tabular}{l|l|l}
\hline Variáveis & Subgrupos & \multicolumn{1}{|c}{ Valor de p } \\
\hline 1. Atuaçáo na Educaçáo Especial* & $\begin{array}{l}\text { 1. Sim }(\mathrm{n}=23) \\
\text { 2. Não }(\mathrm{n}=21)\end{array}$ & $\mathrm{p}=0,380$ \\
\hline 2. Idade & $\begin{array}{l}\text { 1. Mais jovens: até } 40 \text { anos }(\mathrm{n}=25) \\
\text { 2. Mais velhos }(\mathrm{n}=27)\end{array}$ & $\mathrm{p}=0,582$ \\
\hline 3. Escolaridade & $\begin{array}{l}\text { 1. Pós-Graduação }(\mathrm{n}=25) \\
\text { 2. Graduaçáo }(\mathrm{n}=27)\end{array}$ & $\mathrm{p}=0,043^{* *}$ \\
\hline 4. Trabalhos entregues & $\begin{array}{l}1.4 \text { ou } 5 \text { atividades }(\mathrm{n}=36) \\
2.3 \text { ou menos atividades }(\mathrm{n}=16)\end{array}$ & $\mathrm{p}=0,275$ \\
\hline 5. Horas de participaçáo & $\begin{array}{l}1.55 \text { a } 60 \text { horas }(\mathrm{n}=31) \\
2.50 \text { horas ou menos }(\mathrm{n}=21)\end{array}$ & $\mathrm{p}=0,116$ \\
\hline
\end{tabular}

* Foram considerados apenas os participantes que se declararam professores. As demais, mesmo com a declaração de graduada na área da Educação, não foram inseridas na análise, pois não necessariamente atuavam como professoras.

** Diferença estatisticamente significante.

Mesmo não havendo diferença prévia significante, as variáveis sob análise podem representar diferentes influências que as atividades do curso podem exercer sobre as atitudes sociais em relação à inclusão escolar. A formação e a mudança de atitudes sociais podem não sofrer igualmente os efeitos de diferentes variáveis envolvidas. Para verificar essa possibilidade, foi realizada a comparação dos escores do pré-teste com os do pós-teste dos subgrupos de cada uma das variáveis por meio da prova de Wilcoxon. O resultado dessa análise pode ser observado na Tabela 3.

\section{Tabela 3}

Comparação de pré-teste com pós-teste dos subgrupos para cada uma das variáveis

\begin{tabular}{|c|c|c|c|c|c|c|}
\hline Variáveis & Subgrupos & Medida & Min-Max & Md & Q1-Q3 & Valor de $p$ \\
\hline \multirow{3}{*}{$\begin{array}{l}\text { 1. Atuação na } \\
\text { Educaçáo Especial }\end{array}$} & \multirow{2}{*}{ 1.1. $\operatorname{Sim}(n=23)$} & Pré-teste & $104-147$ & 143 & $139-145$ & \multirow{2}{*}{$\mathrm{p}=0,014^{*}$} \\
\hline & & Pós-teste & $123-150$ & 146 & $141-148$ & \\
\hline & 1.2. Não $(n=29)$ & $\begin{array}{l}\text { Pré-teste } \\
\text { Pós-teste }\end{array}$ & $\frac{37-150}{130-150}$ & $\frac{139}{142}$ & $\frac{132-146}{1375-145.5}$ & $\mathrm{p}=0,083$ \\
\hline \multirow{4}{*}{ 2. Idade } & \multirow{2}{*}{$\begin{array}{l}\text { 1. Mais jovens: até } 40 \text { anos } \\
(\mathrm{n}=25)\end{array}$} & Pré-teste & $\frac{130-1) 0}{125-150}$ & $\frac{142}{144}$ & $\frac{1.3 / .3-14), 2}{138-146}$ & \multirow[b]{2}{*}{$\mathrm{p}=0,037^{*}$} \\
\hline & & Pós-teste & $130-150$ & 143 & $138-146$ & \\
\hline & \multirow{2}{*}{$\begin{array}{l}\text { 2. Mais velhos acima de } 41 \\
(\mathrm{n}=27)\end{array}$} & Pré-teste & $37-147$ & 140 & $131-144$ & \multirow{2}{*}{$\mathrm{p}=0,043^{*}$} \\
\hline & & Pós-teste & $123-150$ & 145 & $140-148$ & \\
\hline \multirow{3}{*}{ 3. Escolaridade } & \multirow{2}{*}{ 1. Pós-Graduação $(\mathrm{n}=25)$} & Pré-teste & $94-150$ & 140 & $136,5-145$ & \multirow{2}{*}{$\mathrm{p}=0,698$} \\
\hline & & Pós-teste & $130-150$ & 144 & $138-148.5$ & \\
\hline & 2. Graduação $(\mathrm{n}=27)$ & $\begin{array}{l}\text { Pré-teste } \\
\text { Pós-teste }\end{array}$ & $\frac{37-150}{123-150}$ & $\frac{144}{143}$ & $\frac{134-146}{138-147}$ & $\mathrm{p}=0,000^{*}$ \\
\hline \multirow{4}{*}{$\begin{array}{l}\text { 4. Trabalhos } \\
\text { entregues }\end{array}$} & \multirow{2}{*}{ 1. 4 ou 5 atividades $(n=36)$} & Pré-teste & $104-150$ & 140 & $135-144$ & \multirow{2}{*}{$\mathrm{p}=0,001^{*}$} \\
\hline & & Pós-teste & $123-150$ & 144.5 & $138-148$ & \\
\hline & \multirow{2}{*}{$\begin{array}{l}\text { 2. } 3 \text { ou menos atividades } \\
(\mathrm{n}=16)\end{array}$} & Pré-teste & $37-150$ & 144,5 & $138-146,75$ & \multirow{2}{*}{$\mathrm{p}=0,489$} \\
\hline & & Pós-teste & $137-149$ & 142,5 & $141-146$ & \\
\hline \multirow{3}{*}{$\begin{array}{l}\text { 5. Horas de } \\
\text { participaçáo }\end{array}$} & 1.55 a 60 horas $(n=31)$ & $\begin{array}{l}\text { Pré-teste } \\
\text { Pós-teste }\end{array}$ & $\frac{104-147}{123-150}$ & $\frac{140}{144}$ & $\frac{134-144}{137-147}$ & \multirow{2}{*}{$\mathrm{p}=0,004^{*}$} \\
\hline & \multirow{2}{*}{$\begin{array}{l}\text { 2. } 50 \text { horas ou menos ( } \mathrm{n} \\
=21)\end{array}$} & Pré-teste & $37-150$ & 144 & $138,5-146,5$ & \\
\hline & & Pós-teste & $137-150$ & 143 & $141-147$ & $\mathrm{p}=0,276$ \\
\hline
\end{tabular}

* Diferença estatisticamente significante.

Legenda: Min = menor escore; Max = maior escore; Md = mediana; Q1 = primeiro quartil; Q3 = terceiro quartil. 
Os participantes que atuavam na Educação Especial apresentaram mudança significante nas atitudes sociais em relação à inclusão após o curso $(\mathrm{p}=0,014)$. Os que não atuavam em Educação Especial também apresentaram mudança, mas não significante $(p=0,083)$. Já a idade dos participantes não teve efeito diferencial. Tanto os mais jovens ( $p=0,037)$ quanto os mais velhos ( $\mathrm{p}=0,043)$ apresentaram mudanças significantes. $\mathrm{O}$ nível de escolaridade teve efeito diferencial muito acentuado. Antes do curso, os participantes com formação em nível de Pós-Graduação apresentaram atitudes sociais significantemente diferentes em relação às dos participantes apenas com Graduação (Tabela 2). Submetidos ao curso, os pós-graduados não apresentaram mudança significante $(\mathrm{p}=0,698)$, ao passo que os somente graduados apresentaram mudança significante muito expressiva $(\mathrm{p}=0,000)$. Os participantes que entregaram mais atividades apresentaram mudança nas atitudes sociais ( $\mathrm{p}=0,001)$, o que não ocorreu com quem entregou menos atividades $(\mathrm{p}=0,489)$. Finalmente, o tempo de participação no curso também mostrou relação com a mudança nas atitudes sociais. O subgrupo com mais tempo de participação no curso apresentou diferença significante entre o pré-teste e o pós-teste ( $p=0,004)$, e aquele com menos tempo de participação não apresentou mudança significante $(\mathrm{p}=0,276)$.

Esses resultados mostram que mesmo as variáveis que podem não ter efeito diferencial sobre as atitudes sociais formadas são capazes de afetar diferentemente a suscetibilidade à mudança nelas.

\section{Discussâo}

Este estudo teve como propósito verificar se um programa formativo, o qual continha estratégias educacionais concretas para o trabalho com o estudante com TEA, fundamentado na ABA, poderia tornar as atitudes sociais mais favoráveis ao processo inclusivo por parte de agentes educacionais, como pais, professores e outros profissionais da Educação. O objetivo do programa formativo não era propriamente modificar as atitudes sociais, mas oferecer estratégias educacionais concretas favoráveis à inclusão do estudante com TEA em classe de ensino comum. O estudo baseou-se na hipótese de que o potencial empírico da ABA (Cooper et al., 2007; Higbee et al., 2016; Maurice et al., 1996), que sugere possibilidades efetivas de intervenção por meio de elementos concretos de manejo de comportamento, poderia tornar as atitudes sociais desses agentes educacionais mais favoráveis à inclusão. A hipótese foi confirmada com modificações das atitudes sociais após a formação, mesmo sem a apresentação de qualquer atividade relacionada diretamente à modificação das atitudes sociais. Tal aspecto justifica a originalidade da pesquisa e avança sobre os achados relacionados às variáveis pessoais relevantes para a construção da Educação Inclusiva.

As evidências favoráveis à hipótese foram encontradas e apresentadas na Tabela 1. A diferença entre o pré-teste e o pós-teste é estatisticamente significante ( $p=0,003)$. Os valores calculados sugerem que houve mudança no sentido de as atitudes sociais se tornarem mais favoráveis após o curso. Essa mudança nas atitudes sociais pode ter ocorrido na extensão em que os participantes puderam verificar a possibilidade concreta de atuação junto a estudantes com TEA, considerando a natureza prática de intervenção comportamental imediatamente sugerida pela ABA. Reforçam essa tese os achados de Torres e Mendes (2019), que não encontraram efeito positivo do programa formativo em cursos de licenciatura. As próprias autoras sugerem a 
possibilidade de não ter havido mudança nas atitudes sociais em função do conteúdo desse programa formativo, que tratou de três eixos de fundamentação da Educação Inclusiva: história, políticas e práticas pedagógicas. Com esse conteúdo, os cursistas podem não ter vislumbrado possibilidades concretas de promover a inclusão escolar em estudantes com deficiência.

Apenas conhecimentos teóricos a respeito de inclusão adquiridos em curso de capacitação parecem insuficientes para a mudança de atitudes sociais. Os estudos de Shade e Stewart (2001), Lenka e Parua (2012) e Vieira (2014) revelam mudanças significantes nas atitudes sociais em função do curso de capacitação. Nesses estudos, além de conhecimentos teóricos, foram utilizadas diferentes atividades práticas, como dramatização e simulação de construção de atitudes sociais favoráveis (Shade \& Stewart, 2001) e vivência no ensino de alunos com deficiência (Lenka \& Parua, 2012). No estudo de Vieira (2014), as atividades desenvolvidas pelos professores estavam planejadas com base em algumas técnicas de mudança de atitudes sociais.

As atividades práticas, quando planejadas com o propósito específico de mudança de atitudes sociais, podem até ser relativamente breves, não comprometendo a carga horária reservada para os conhecimentos teóricos relacionados a fundamentos da Educação Inclusiva, que são também importantes. No estudo de Menino-Mencia (2020), a introdução de um breve workshop foi suficiente para produzir mudanças favoráveis nas atitudes sociais dos cursistas em relação à inclusão. Esse workshop de duas sessóes de duas horas fora planejado especificamente para promover a mudança de atitudes sociais em relação à inclusão. Nesse sentido, é promissora a possibilidade de cursos de capacitação de professores introduzirem breves atividades que resultem em atitudes sociais mais favoráveis em relação à inclusão.

Neste estudo, o programa formativo compreendeu duas partes. Uma mais geral de fundamentação teórica, a qual versava sobre o panorama geral da Educação Especial na perspectiva inclusiva (Parte 1 do Quadro 1); e uma mais específica sobre fundamentos da ABA e trabalho com o estudante com TEA (Parte 2 do Quadro 1). A mudança nas atitudes sociais possivelmente deveu-se aos conteúdos e às atividades que permitiram aos educadores participantes vislumbrar alternativas viáveis e concretas de enfrentamento das dificuldades vivenciadas no cotidiano na Educação Inclusiva.

As atitudes sociais têm componentes cognitivo, afetivo e comportamental, o que sugere multideterminação na sua formação. Em vista da heterogeneidade dos participantes, procedeu-se à identificação de variáveis pessoais com vistas a avaliar a participação delas na formação e na mudança de atitudes sociais em relação à inclusão.

Os dados da Tabela 2 indicam que, antes da intervenção, foi encontrada diferença significante apenas entre os participantes com formação em nível de Pós-Graduação e os de Graduação. Variáveis como a idade e a experiência em Educação Especial sugerem a possibilidade de estreita relação com as atitudes sociais, o que não se verificou neste estudo.

A revisão de pesquisas brasileiras sobre atitudes sociais em relação à inclusão aponta resultados inconclusivos (Omote, 2018). Há estudos que evidenciaram atitudes sociais mais favoráveis em participantes mais velhos que em mais jovens, mas há outros estudos em que não foi encontrada diferença em função da idade dos participantes. Resultado semelhante foi verificado em relação à experiência de contato prévio com estudantes com deficiência. A experiência 
com pessoas com deficiência pode tanto tornar as atitudes sociais mais favoráveis quanto não exercer efeito sobre elas.

Os estudos sobre as atitudes sociais em relação à inclusão são predominantemente descritivos, caracterizando-as para diferentes grupos de participantes em função de variáveis sociodemográficas, como idade, gênero, formação, contato com pessoas com deficiência, escolaridade etc. Há necessidade de realizarem-se estudos longitudinais para descrever o processo de formação dessas atitudes, com o intuito de identificar variáveis criticamente relacionadas a ele. Entretanto, parece plausível a hipótese de que as crianças estejam sendo submetidas essencialmente a um conjunto comum de crenças, sentimentos e açóes direcionadas a pessoas com deficiência, com uma visão estereotipada a respeito de deficiências e de pessoas com deficiência. Somente ao vivenciarem situaçóes especiais, as pessoas podem apresentar atitudes sociais diferenciadas, possivelmente por ter acesso a informaçóes mais específicas e diversificadas em vez de estereótipos, preconceitos e estigmas.

A inclusão explicitou a necessidade de modificar atitudes sociais de pessoas comuns, para que o convívio, seja na escola ou na comunidade em geral, possa ocorrer de modo harmonioso e produtivo para todas as partes envolvidas. Há, hoje, particular interesse em desenvolver procedimentos de mudança de atitudes sociais em relação à inclusão. Com o intuito de contribuir para a identificação de variáveis criticamente relacionadas a essa mudança, os dados foram reorganizados para estudar os efeitos diferenciais de cada uma das cinco variáveis consideradas neste estudo.

O efeito das atividades do curso sobre as atitudes sociais em relação à inclusão variou conforme algumas características dos cursistas, conforme a Tabela 3, o que recomenda novos estudos para a identificação das variáveis criticamente relacionadas à mudança de atitudes sociais. Isso certamente contribuirá, na formação inicial e continuada de professores, com a definição mais acertada sobre as atividades e os conteúdos que, além da formação para a adequada compreensão do problema e o uso de recursos apropriados para cada situação, contribuam para tornar as atitudes sociais dos professores mais favoráveis à inclusão. Tal formação é fundamental, pois as açóes desenvolvidas em relação a estudantes público-alvo da Educação Especial se integram aos sentimentos e às crenças em relação à inclusão deles.

A análise da Tabela 3 revela que o nível de escolaridade foi a variável com efeito diferencial mais acentuado sobre a mudança de atitudes sociais. Os participantes com apenas formação em nível de Graduação apresentaram mudança expressiva nas atitudes sociais em decorrência da participaçáo no curso $(\mathrm{p}=0,000)$, ao passo que, para os participantes com formação em nível de Pós-Graduação, a participação no curso não surtiu efeito ( $\mathrm{p}=0,698)$. Ao considerar que, antes da participação no curso, havia sido verificada diferença significante entre esses dois subgrupos, cabe aventar a hipótese de que os participantes com Pós-Graduação podem requerer atividades mais avançadas que os participantes com somente a Graduação.

As demais variáveis, com exceção da idade, tiveram efeitos diferenciais sobre a mudança de atitudes sociais em decorrência da participação no curso. Os participantes com atuação na Educação Especial apresentaram mudanças significantes nas atitudes sociais com a participação no curso ( $\mathrm{p}=0,014)$, o que não ocorreu com a mesma magnitude com seus pares sem essa experiência $(p=0,083)$. Os cursistas com experiência na Educação Especial poderiam 
estar mais suscetíveis aos efeitos das atividades desenvolvidas, percebendo mais imediatamente as novas perspectivas de atuação com a ABA, comparativamente a seus pares sem experiência de enfrentamento de desafios colocados pela inclusão de estudantes com deficiência.

Esses resultados sugerem a necessidade de as atividades de formação serem diferenciadas em função do nível de escolaridade e da experiência prévia na área da Educação Especial. Seguramente, outras variáveis devem ser identificadas para que se organize a programação de conteúdos e de atividades adequadas para diferentes perfis de participantes.

As duas variáveis relacionadas à participação no curso (número de trabalhos entregues e o tempo de participação no curso) também têm efeitos diferenciais. Parece relativamente óbvio que os cursistas que entregaram mais trabalhos e que participaram mais assiduamente tenham apresentado mudança nas atitudes sociais, o que não se verificou com seus pares com menor participação. No pré-teste, em relação a essas duas variáveis, não havia diferença significante entre os subgrupos, o que sugere a possibilidade de que, ao menos em parte, a mudança nas atitudes sociais pode ser resultado da participação mais intensa. Isso indica que, nos cursos de capacitação, é necessário também considerar atividades capazes de assegurar maior motivação para participação.

\section{Conclusão}

A formação de professores para a Educação Inclusiva não pode limitar-se a repassar-lhes informaçóes e fundamentos teóricos nem conhecimentos sobre os diferentes recursos especiais existentes para promover a educação de estudantes com alguma necessidade educacional especial. As ações dos professores são orientadas por suas atitudes sociais, que precisam ser objeto de intervenção em qualquer capacitação deles. No caso particular do aluno com TEA, essa necessidade pode ser mais acentuada, pois trata-se de uma condiçáo relativamente nova no contexto de escolas de ensino comum.

A formação de professores fundamentada na ABA demonstrou ser eficiente para a mudança de atitudes sociais deles em relação à inclusão. Tal mudança se deveu possivelmente ao fato de o conteúdo e as atividades do curso terem permitido aos professores visualizarem a possibilidade de intervenção efetiva junto a estudantes com TEA. Algumas variáveis pessoais dos professores parecem favorecer essa mudança nas atitudes sociais, o que sugere a necessidade de os cursos de formação serem planejados em função de perfis específicos de professores a que se destinam.

A reunião de diferentes agentes educacionais mostrou interesse plural sobre a temática, uma vez que a ampla variedade de experiências estava representada no curso. A parceria entre a Universidade e a Secretaria Municipal de Educação pode ser considerada uma estratégia assertiva na formação continuada de docentes.

O curso não foi organizado apenas no formato de palestra, com propósito informacional, pois também envolveu o planejamento de atividades práticas de aplicação dos conhecimentos em suas rotinas com a devida documentação por meio de relatórios. O estudo de caso com a elaboraçáo de programa individualizado de intervençáo, previsto no último módulo, permitiu que os participantes tivessem a oportunidade de avaliar o repertório de entrada de 
um estudante com TEA, conhecer as especificidades do estudante e, a partir daí, planejar uma atividade de ensino para um comportamento específico.

Os resultados deste estudo s somam-se à literatura sobre as possibilidades de construção de um contexto escolar com atitudes sociais mais favoráveis à inclusão, envolvendo diferentes agentes educacionais.

\section{REFERÊNCIAS}

Associação Americana de Psiquiatria. (2013). Manual diagnóstico e estatístico de transtornos mentais texto revisado (5a. ed.). Artes Médicas.

Almeida-Verdu, A. C., Hubner, M. M., Fagiiani, R. B., Canovas, D. S., \& Lemos, M. S. (2012). Aquisição de linguagem e habilidades pré-requisitos em pessoas com transtorno do espectro autista. Revista DI, 3, 36-42.

Benitez, P., \& Domeniconi, C. (2015). Inclusão Escolar: o papel dos agentes educacionais brasileiros. Psicologia: Ciência e Profissão, 35, 1007-1023. https://doi.org/10.1590/1982-3703000652014

Benitez, P., Gomes, M., Bondioli, R., \& Domeniconi, C. (2017). Mapeamento das estratégias inclusivas para estudantes com deficiência intelectual e autismo. Psicologia em Estudo, 22(1), 81-93. https:// doi.org/10.4025/psicolestud.v22i1.34674

Calheiros, D., \& Mendes, E. G. (2016). Consultoria colaborativa a distância em tecnologia assistiva para professores. Cadernos de Pesquisa, 46, 1100-1123. https://doi.org/10.1590/198053143562

Carvalho, F. A., Paula, C. S., Teixeira, M. C. T. V., Zaqueu, L. C. C., D'Antino, M. E. F. (2013). Rastreamento de sinais precoces de transtorno do espectro do autismo em crianças de creche de um município de São Paulo. Psicologia: Teoria e Prática, 15(2), 144-154.

Cooper, J. O., Heron, T. E., \& Heward, W. L. (2007). Applied behavior analysis (2a ed.). Pearson Education.

Domeniconi, C., Zaine, I., \& Benitez, P. (2012). Princípios e métodos para o ensino de comportamentos novos a pessoas com deficiência intelectual. Revista DI, 3, 31-35.

França, E. S., \& Munford, D. (2012). Diferenças na sala de aula: conhecendo a prática pedagógica de duas professoras de ciências. Investigaçôes em Ensino de Ciências, 17(3), 593-614.

Gomes, C. G. S., \& Silveira, A. D. (2016). Ensino de habilidades básicas para pessoas com autismo. Appris.

Gomes, C. G. S., Souza, D. G., Silveira, A. D., \& Oliveira, I. M. (2017). Intervenção comportamental precoce e intensiva com crianças com autismo por meio da capacitação de cuidadores. Revista Brasileira de Educação Especial, 23(3), 377-390. https://doi.org/10.1590/s1413-65382317000300005

Higbee, T. S. (2012). The ASSERT Curriculum. Unpublished manuscript, Department of Special Education and Rehabilitation, Utah State University, Logan, Utah, USA.

Higbee, T. S., Aporta, A. P., Resende, A., Nogueira, M., Goyos, C., \& Pollard, J. S. (2016). Interactive computer training to teach discrete-trial instruction to undergraduates and special educators in Brazil: a replication and extension. Journal of Applied Behavior Analysis, 49, 1-14. https://doi. org/10.1002/jaba.329 
Lei no 12.764, de 27 de dezembro de 2012. Institui a Política Nacional de Proteção dos Direitos da Pessoa com Transtorno do Espectro Autista. http://www.planalto.gov.br/ccivil_03/_ato20112014/2012/lei/l12764.htm

Lenka, S. K., \& Parua, R. K. (2012). Effect of Included Experience Program on the Attitudes of PreService Teachers towards Students with Special Needs. Journal of Education and Practice, 3(12), 61-66.

Maurice, C., Luce, S. C., \& Green, G. (1996). Behavioral intervention for young children with autism: a manual for parents and professionals. Proed.

Mendes, E. G. (2006). A radicalização do debate sobre Inclusão Escolar no Brasil. Revista Brasileira de Educação, 11(33), 387-405. https://doi.org/10.1590/S1413-24782006000300002

Menino-Mencia, G. F. (2020). Influência de um programa de formação continuada sobre crenças e atitudes dos professores em relação a Educação Inclusiva [Tese de Doutorado, Faculdade de Ciências, Universidade Estadual Paulista - UNESP]. Repositório da UNESP. https://repositorio.unesp.br/ handle/11449/192128

Monico, P. A. M., Saraiva, L. A., \& Orlando, R. M. (2018). Formação inicial de professores na perspectiva inclusiva: levantamento de produçóes. Psicologia Escolar e Educacional, 22(n. spe), 41-48. https:// doi.org/10.1590/2175-3539/2018/040

Omote, S. (1999). Normalização, integração, inclusão. Ponto de Vista, 1(1), 4-13.

Omote, S. (2005). A construção de uma escala de atitudes sociais em relação à inclusão: notas preliminares. Revista Brasileira de Educação Especial, 11(1), 33-47.

Omote, S. (2013). Atitudes sociais em relação à inclusão: estudos brasileiros. Revista Ibero-Americana de Estudos em Educação, 8, 639-649.

Omote, S. (2016). Escala de Atitudes Sociais em relação à inclusão. Journal of Research in Special Educational Needs, 16, 470-473. https://doi.org/10.1111/1471-3802.12308

Omote, S. (2018). Atitudes sociais em relação à inclusão: recentes avanços em pesquisa. Revista Brasileira de Educação Especial, 24, 21-32. https://doi.org/10.1590/s1413-65382418000400003

Organização das Naçóes Unidas. (2015). Objetivo 4: assegurar a Educação Inclusiva e equitativa e de qualidade e promover oportunidades de aprendizagem ao longo da vida para todos. https://nacoesunidas. org/pos2015/ods4/

Organização das Naçóes Unidas para a Educação, a Ciência e a Cultura. (1994). Declaração de Salamanca e linha de Ação sobre Necessidades Educativas Especiais. Unesco.

Organização das Naçóes Unidas para a Educação, a Ciência e a Cultura. (1990). Declaração Mundial sobre Educação para Todos: satisfação das necessidades básicas de aprendizagem. Unesco.

Pletsch, M. D. (2009). A formação de professores para a Educação Inclusiva: legislação, diretrizes políticas e resultados de pesquisas. Educar em revista, 33, 143-156. https://doi.org/10.1590/S010440602009000100010

Política Nacional de Educação Especial na perspectiva da Educação Inclusiva. (2008). http://portal. mec.gov.br/docman/dezembro-2014-pdf/16690-politica-nacional-de-educacao-especial-naperspectiva-da-educacao-inclusiva-05122014

Rodrigues, I. B., Moreira, L. E. V., \& Lerner, R. (2012). Análise institucional do discurso de professores de alunos diagnosticados como autistas em Inclusão Escolar. Psicologia: Teoria e Prática, 14, 70-83. 
Schmidt, C. (2017). Transtorno do espectro autista: onde estamos e para onde vamos. Psicologia em Estudo, 22(2), 221-230. https://doi.org/10.4025/psicolestud.v22i2.34651

Schmidt, C., Nunes, D. R. de P., Pereira, D. M., Oliveira, V. F. de, Nuernberg, A. H., \& Kubaski, C. (2016). Inclusão Escolar e autismo: uma análise da percepção docente e práticas pedagógicas. Psicologia: Teoria e Prática, 18(1), 222-235.

Shade, R. A., \& Stewart, R. (2001). General Education and Special Education preservice teachers' attitudes toward inclusion. Preventing School Failure, 46(1), 37-41.

Torres, J. P., \& Mendes, E. G. (2019). Atitudes Sociais e Formação Inicial de Professores para a Educação Especial. Revista Brasileira de Educação Especial, 25(4), 765-780. https://doi.org/10.1590/s141365382519000400014

Velloso R. L., Vinic, A. A., Duarte, C. P., Dantino, M. E. F., Brunoni, D., \& Schwartzman, J. S. (2011). Protocolo de avaliação diagnóstica multidisciplinar da equipe de transtornos globais do desenvolvimento vinculado à pós-graduação em distúrbios do desenvolvimento da Universidade Presbiteriana Mackenzie. Caderno de Pós-Graduação em Distúrbios do Desenvolvimento, 11(1), 9-22.

Vieira, C. M. (2014). Atitudes sociais em relação à inclusão: efeitos da capacitação de professores para ministrar programa informativo aos alunos [Tese de Doutorado, Faculdade de Filosofia e Ciências de Marília, Universidade Estadual Paulista - UNESP]. Repositório da UNESP. https://repositorio. unesp.br/handle/11449/114037

Vilaronga, C. A. R., \& Mendes, E. G. (2017). Formação de professores como estratégia para realização do coensino. Diálogos e perspectivas em Educação Especial, 4, 19-31. https://doi.org/10.36311/23588845.2018.v4n1.03.p19

Williams, L. C. A., \& Aiello, A. L. R. (2001). O inventário Portage Operacionalizado: intervenção com familias. Memmon.

Recebido em: 30/06/2020

Reformulado em: 09/11/2020

Aprovado em: 31/12/2020 